\title{
How Should We Teach Young Adults to Handle Their Sensitive Infor- mation and Personal Data with Caution?
}

\author{
Frauke Prott \\ Technical University of Applied Sciences \\ Wildau
}

\begin{abstract}
Digitization and the mobile devices, services, and opportunities that go with it are omnipresent in the life of adolescents. However, information security and data protection are seldom taught in school. The paper presents a research and application project that aims to sensitize Year-Nine pupils and raise their awareness and sense of caution in how they handle sensitive information and their own personal data as well as that of others. The development and implementation of this pilot action is based on research into computer science curricula and insights into the effectiveness of game-based learning as an educational method. The project develops and evaluates a learning station format with game-based scenarios addressing important information security issues that are relevant for the pupils and part of their daily life. The very positive evaluation of the pilot action and the individual learning stations by the participating pupils militates in favour of a game-based approach as a means to sensitize young adults and foster a competent and responsible way of handling sensitive information and personal data.
\end{abstract}

\section{Introduction}

In Germany almost every young adult aged between twelve and nineteen (97\%) uses a smartphone [1]. However, information security and data protection seem to be seldom taught in school. This suggests our own survey with 281 Year-Eight pupils - 65.5 per cent of whom indicate that topics such as secure passwords, safe behaviour in social networks, and the safe usage of apps and internet services - is not discussed in school lessons. Because the ubiquity of mobile devices and the accompanying services and opportunities also involve risks, it is important to sensitize children and young adults and train them to develop a careful and secure approach to using mobile devices and handling personal data and sensitive information, both their own and that of other people. At the same time, many teachers and parents seem to be overwhelmed with awareness-raising on the ever-shrinking technological cycles and increasing challenges of digitization.

\author{
Margit Scholl \\ Technical University of Applied Sciences \\ Wildau
}

\section{Research and methodological back- ground}

\subsection{Computer science curricula}

A current study states that young people, and in particular girls, are less interested in information security as a career field [2]. Computer science coursework and the way computer science is taught in schools are often mentioned as reasons for a lack of interest in the subject [3]. The challenge lies in developing age-appropriate curricula for information security with effective teaching and learning methods [4]. Several studies and research projects recommend the use of problem-based tasks embedded in authentic, real-world contexts that illustrate the day-to-day relevance of the topic, while at the same time engaging the (inter)active and productive collaboration of pupils in solving the given problem [5]. The recommended teaching and learning methods should arouse interest in the topic of information security and boost the self-confidence of pupils with regard to their information security and data protection competencies.

Moreover, it is well known that only a small proportion of the learning and anchoring of knowledge is achieved through listening and reading (20\%). Studies suggest that learning success can be increased by up to 90 per cent by means of active practice. It is therefore important for pupils to actively engage in problem-based activities in order to enhance cognition [4].

\subsection{Game-based learning}

A teaching and learning method that is increasingly attracting positive attention in meeting these requirements is game-based learning (GBL). GBL is described as an enjoyable and motivating form of learning [6]. Another term often used in this context is gamification. Gamification means the application of game elements in non-game contexts such as working or learning processes [7]. Some of the typical game elements are points, badges, leader boards, challenges, and levels $[8,9]$.

The clear targets and immediate feedback which games offer are attributes that are also beneficial in 
learning contexts [10]. With the help of GBL scenarios, pupils can practise, experience, and experiment with a topic more profoundly and deal with any repercussions and follow-up situations in a secure environment [11].

Many studies reveal the effectiveness of these game characteristics and the positive impact of GBL scenarios in learning contexts. GBL requires a high level of involvement, which actively supports the learning process of pupils [12]. GBL scenarios improve learning outcomes over the short and long term $[13,14]$. The application of GBL generates better learning outcomes as compared with traditional lectures [15]. Moreover, GBL scenarios increase motivation and induce behavioural changes [16].

In addition, a collaborative approach in solving GBL scenarios enables social learning in a team. The advantages of social learning are the exchange of experiences and knowledge between the team members as well as the strengthening of communication and team skills [17]. From the authors' own experience, a good GBL scenario requires a strong reduction in thematic complexity, a good and realistic story, entertaining interaction, clear goals and multiple revisions based on feedback from the target group.

With this in mind, the first research question that should be answered in this paper is this: Does the pilot action increase young people's interest in and awareness of information security and data protection and induce behavioural changes?

\subsection{Single-sex education}

Studies in the field of educational sciences show the beneficial results of single-sex education in subjects that are considered to belong to a male domain. Thus, girls perform better in subjects like mathematics and natural sciences and are more likely to choose these subjects as options if they are taught in classes consisting only of girls [18]. Female pupils who attend single-sex physics courses also tend to have a higher regard for their own abilities in the subject [19]. A possible explanation for these findings could be that co-educational reinforce gender stereotypes [18].

The fact that girls tend to be less interested in information security as a career field leads us to the second research question that will be answered in this paper: Do female pupils prefer to tackle GBL scenarios in the field of information security and data protection in single-sex teams?

\section{3. "Security" project}

The project "Gender-Sensitive Study and Vocational Orientation for the Occupation Security Specialist" (abbreviated to "Security"), which is being conducted in Germany and funded by the Federal Ministry of Education and Research, is designed to arouse the interest of young people, in particular girls, in the innovative and forward-looking career field of information security.

The project presents the career field in an appealing and gender-sensitive way, offering portraits of female role models working in the field of information security and an interactive and practically oriented pilot action. In this way, pupils learn that the career has many different facets, and this is mirrored in the study courses and vocational trainings associated with it.

The focus of this paper is on the pilot action. Using GBL scenarios, this action aims to raise awareness among young adults that information security and data protection are already part of their everyday lives and to sensitize them to the need for cautious and conscious handling of their personal data and sensitive information as well as that of others. In addition, the pilot action lets pupils experience one of the key tasks carried out by professionals working in the field of information security-namely, sensitizing people to information security and offering training to support the process.

The pilot action consists of six learning stations, comparable to circuit training in sport. The procedure of each station is similar and can be divided into three short phases. In the first phase, participants are familiarized with the station's particular topic, and the moderator at the station encourages the young adults to share the knowledge and experience they have on the subject. During the second phase-the gaming phase - a team of pupils jointly tackle the game-based task. In the third phase, the pupils reflect on their results with the moderator, and the moderator discusses further questions with them and provides practical advice. Each phase only takes about five minutes.

Each station addresses an important issue in information security and data protection. The following figure shows the six learning stations.
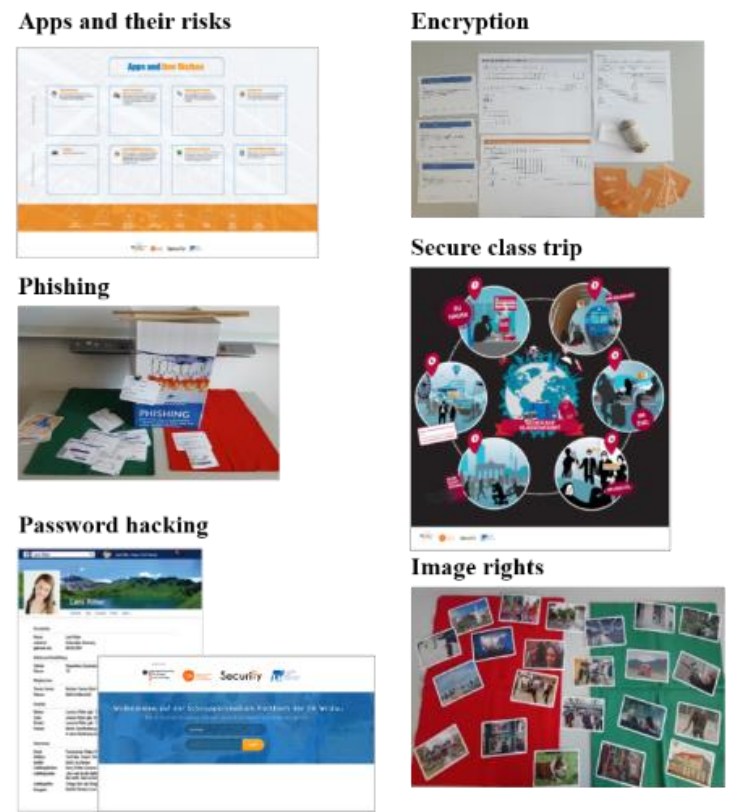

Figure 1. Images of the learning stations 
At the "Apps and their risks" station, the young adults are sensitized to and acquire knowledge regarding the possible risks of apps. This encourages them to think about the usage of special apps and how to use these apps with an awareness of the risks involved. The "Phishing" station promotes sensitivity about the threat of phishing e-mails and provides knowledge about phishing characteristics to make the identification of phishing e-mails easier. The following station, "Password hacking", invites the pupils to take the role of a hacker and to guess the possible passwords of a fictitious person. By means of this role play, the young adults learn how to create strong and easily memorable passwords. A more difficult topic is dealt with at the "Encryption" station. Here, the basics of encryption and its usage are discussed. The pupils are familiarized with the complex topic through the application of easy coding procedures, which involve the opening of an encrypted lock. At the "Secure class trip" station, the participants are confronted with possible risks to their own person, their belongings, or their information and data in public spaces. Besides identifying the risks, they also learn which protective measures they can adopt to avoid or at least minimize these risks. The last station, "Image rights", deals with the legal recording and use of pictures. It makes the young adults aware of the fact that they are not allowed to photograph every subject they see or use every picture they find online. Instead, they get to know the creative commons (CC) license and the protocols they should follow in using CC-licensed work or materials protected by copyright.

The pilot action is conducted in four German schools with Year-Nine pupils from different social backgrounds. The GBL scenarios are oriented to the everyday life and needs of adolescents and therefore represent authentic, real-world contexts. The learning stations offer practical experience and the opportunity to explore important information security and data protection issues in order to raise awareness and promote the development of different skills.

The joint completion of these inspiring and exciting GBL scenarios within a supportive and secure environment should motivate young adults to exchange knowledge and experience and raise their awareness of and competence in information security and data protection.

\section{Results}

The participants were asked to fill out a standardized questionnaire after completing the pilot action to help with its evaluation and answer the two research questions. Over 250 Year-Nine pupils attended the action. Of the 239 respondents to the questionnaire, 38.9 per cent were female, 45.6 per cent male, and 15.5 per cent didn't specify their sex. The pupils were asked to rate their response to given statements on a four-point Likert scale with the anchors "agree", "tend to agree", "tend to disagree", and "disagree". They also had the option to choose the response "I don't know". In addition to this, the pupils were asked to give their feedback on the learning stations geared to a four-point Likert scale with the anchors "good", "fair", "not so good", and "poor". The "I don't know" option was also included here. The number of answers to the individual questions varies, either because the response "I don't know" was selected or because information was omitted or missed out.

\subsection{Overall evaluation of the pilot action}

The overall evaluation of the pilot action was very positive (see figure 2 ). A vast majority (87.5\%) agreed or tended to agree that they had fun in tackling the game-based tasks. In addition, 86.6 per cent agreed or tended to agree that the learning stations were interesting. For almost 80 per cent of the pupils polled, the learning stations address topics relevant to their everyday life. The learning success and intention to apply the acquired knowledge and handle their information and personal data more cautiously in future was also given a favourable rating by a large majority of pupils ( $75.4 \%$ and $74.6 \%$ respectively).

It is interesting to examine the answers provided by male and female participants separately from one another. Apart from the question relating to the fun aspect of the learning stations, a higher percentage of girls always agreed or tended to agree with the given statements. Figures three and four illustrate these findings. 
Overall evaluation of the pilot action (all participants $(\mathrm{N}=215-232)$ )

\begin{tabular}{|c|c|c|c|}
\hline \multirow[t]{2}{*}{ I had fun in solving the learning stations. } & $44.0 \%$ & $43.5 \%$ & $9.9 \%$ \\
\hline & \multicolumn{2}{|c|}{$87.5 \%$} & $0.9 \%$ \\
\hline The learning stations were interesting. & $37.9 \%$ & $48.7 \%$ & $12.5 \%$ \\
\hline \multirow{3}{*}{ The learning stations cover topics relevant to my everyday life. } & \multicolumn{2}{|c|}{$86.6 \%$} & $3.0 \%$ \\
\hline & $38.1 \%$ & $41.6 \%$ & $17.3 \%$ \\
\hline & \multicolumn{2}{|c|}{$79.7 \%$} & \\
\hline \multirow{3}{*}{$\begin{array}{l}\text { I will apply the knowledge I have just learned and will handle my } \\
\text { information and personal data more cautiously in future. }\end{array}$} & $31.2 \%$ & $44.2 \%$ & $20.0 \%$ \\
\hline & \multicolumn{2}{|c|}{$75.4 \%$} & $5.4 \%$ \\
\hline & & & \\
\hline
\end{tabular}

Figure 2. Overall evaluation of the pilot action by the participants

Overall evaluation of the pilot action by female participants $(\mathrm{N}=88-91)$

\begin{tabular}{|c|c|c|c|}
\hline \multirow{2}{*}{ I had fun in solving the learning stations. } & $48,4 \%$ & $37,4 \%$ & $11,0 \%$ \\
\hline & \multicolumn{2}{|c|}{$85.8 \%$} & \\
\hline \multirow[t]{2}{*}{ The learning stations were interesting. } & $40,0 \%$ & $50,0 \%$ & \\
\hline & \multicolumn{2}{|c|}{$90.0 \%$} & \\
\hline \multirow[t]{2}{*}{ The learning stations cover topics relevant to my everyday life. } & $40,7 \%$ & $42,9 \%$ & $15,4 \%$ \\
\hline & \multicolumn{2}{|c|}{$83.6 \%$} & $3,4 \%$ \\
\hline \multirow{3}{*}{$\begin{array}{l}\text { I will apply the knowledge I have just learned and will handle my } \\
\text { information and personal data more cautiously in future. }\end{array}$} & $34,8 \%$ & $48,3 \%$ & $13,5 \%$ \\
\hline & \multicolumn{2}{|c|}{ 83.1\% } & $\%$ \\
\hline & $39,8 \%$ & $43,2 \%$ & $13,6 \%$ \\
\hline
\end{tabular}

Figure 3. Overall evaluation of the pilot action by female participants

Overall evaluation of the pilot action by male participants $(\mathrm{N}=99-107)$

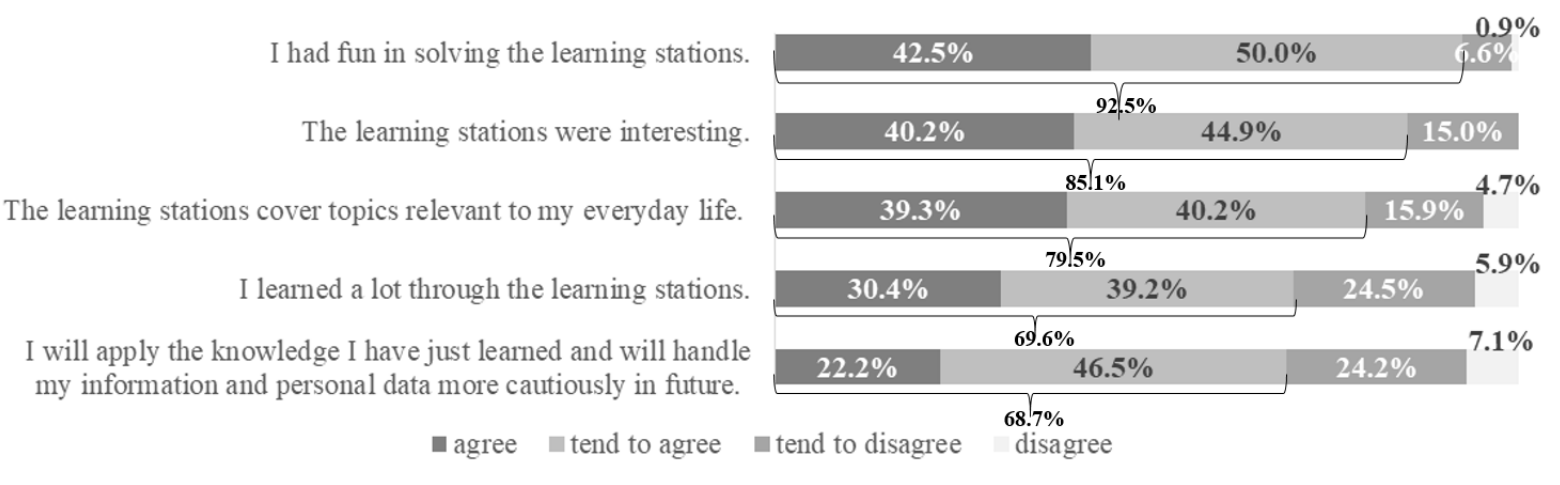

Figure 4. Overall evaluation of the pilot action by male participants 
We also asked the participants about their interest in information security and computer science (see figures 5 and 6). Interestingly, there is only a modest difference in the levels of interest in information security (56.8\% agree or tend to agree) and in computer science (54.4\% agree or tend to agree) for all participants. However, girls are far more interested in information security (52.8\% agree or tend to agree) than in computer science (33\% agree or tend to agree). Girls are less as interested in information security as boys (63.5\% agree or tend to agree), but the difference in interest is far greater for computer science $(73.1 \%$ of the boys agree or tend to agree).

Unfortunately, we are not able to compare the level of interest before and after the pilot action. However, the interest in information security of more than half of the female and male participants respectively underlines the positive overall evaluation of the pilot action.

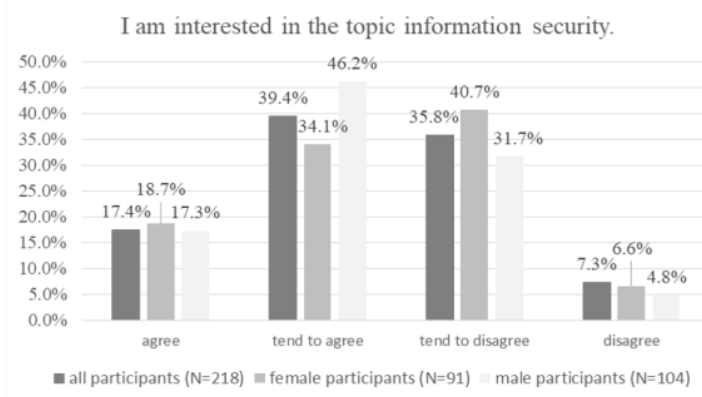

Figure 5. Interest in information security

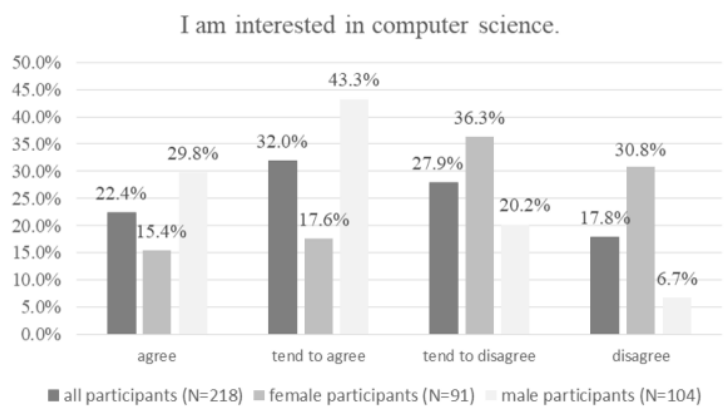

Figure 6. Interest in computer science

\subsection{Popularity of the learning stations}

We also asked the pupils how they liked the individual learning stations. Figure 7 shows the results. Four of the six learning stations appeal to the majority of the pupils polled. "Password hacking", which includes the hacker role play, is by far the most popular learning station-75.8 per cent of participants evaluated it as "good". If we look at the first two response categories ("good" and "fair"), we find that all the learning stations were evaluated as fair or better by at least 77.9 per cent of pupils. The proportion of participants who rated the learning stations as "not so good" and "poor" is under 5 per cent for "Password hacking" and "Apps and their risks", nearly 10 per cent for "Phishing" and "Encryption" and slightly over 22 per cent for "Secure class trip" and "Image rights". Overall, it can be said that all the learning stations were viewed very positively by the young adults.

The popularity of the learning stations does not vary significantly between the sexes (see fig. 8 and 9). Only "Secure class trip" performs better with the girls.

\subsection{Single-sex or mixed-sex teams}

The pupils were randomly assigned to teams of only girls, only boys, or girls and boys. There were 169 respondents to the question as to whether a singlesex or mixed-sex team was preferred. The results are presented in table 1 . Half of the fifty-eight girls in single-sex teams agreed with the statement "I liked the fact that there were only girls in my team", while 19 per cent tended to agree. Around 15.5 per cent disagreed or tended to disagree with this statement and another 15.5 per cent chose the option "I don't know". For the boys-only teams, the level of agreement with the statement "I liked the fact that there were only boys in my team" was lower, with 40.3 percent of the seventy-two boys polled agreeing and 16.7 per cent tending to agree. Conversely, 18 per cent disagreed or tended to disagree with the statement and 25 per cent responded with "I don't know". However, both girls and boys liked being in a mixed-sex team. Of the 16 girls polled in mixed-sex teams, 81.3 per cent agreed and 12.5 per cent tended to agree. The remaining girls chose the response "I don't know". Of the fifteen boys polled in mixed-sex teams, 60 per cent agreed and 26.7 per cent tended to agree. Only 6.7 per cent tended to disagree and 6.7 per cent "didn't know". Eight members of the mixed-sex teams didn't indicate their sex.

Although the majority of the girls polled do not mind being in girls-only settings $(69 \%)$, the girls in the mixed teams had a stronger preference for this setup $(93.8 \%)$.

Table 1. Preference for single- or mixed-sex teams (absolute and as \%)

\begin{tabular}{|c|c|c|c|c|c|}
\hline & agree & $\begin{array}{l}\text { tend to } \\
\text { agree }\end{array}$ & $\begin{array}{l}\text { tend to } \\
\text { disagree }\end{array}$ & disagree & $\begin{array}{l}\text { I don't } \\
\text { know }\end{array}$ \\
\hline Girls' team & $\begin{array}{c}29 \\
(50 \%)\end{array}$ & $\begin{array}{c}11 \\
(19 \%)\end{array}$ & $\begin{array}{c}8 \\
(13.8 \%)\end{array}$ & $\begin{array}{c}1 \\
(1.7 \%)\end{array}$ & $\begin{array}{c}9 \\
(15.5 \%)\end{array}$ \\
\hline Boys' team & $\begin{array}{c}29 \\
(40.3 \%)\end{array}$ & $\begin{array}{c}12 \\
(16.7 \%)\end{array}$ & $\begin{array}{c}7 \\
(9.7 \%)\end{array}$ & $\begin{array}{c}6 \\
(8.3 \%)\end{array}$ & $\begin{array}{c}18 \\
(25 \%)\end{array}$ \\
\hline $\begin{array}{l}\text { Mixed-sex } \\
\text { teams (all) }\end{array}$ & $\begin{array}{c}28 \\
(71.8 \%)\end{array}$ & $\begin{array}{c}7 \\
(17.9 \%)\end{array}$ & $\begin{array}{c}1 \\
(2.6 \%)\end{array}$ & $\begin{array}{c}0 \\
(0 \%)\end{array}$ & $\begin{array}{c}3 \\
(7.7 \%)\end{array}$ \\
\hline $\begin{array}{l}\text { Mixed-sex } \\
\text { teams: girls }\end{array}$ & $\begin{array}{c}13 \\
(81.3 \%)\end{array}$ & $\begin{array}{c}2 \\
(12.5 \%)\end{array}$ & $0(0 \%)$ & $0(0 \%)$ & $\begin{array}{c}1 \\
(6.3 \%)\end{array}$ \\
\hline $\begin{array}{l}\text { Mixed-sex } \\
\text { teams: boys }\end{array}$ & $\begin{array}{c}9 \\
(60 \%)\end{array}$ & $\begin{array}{c}4 \\
(26.7 \%)\end{array}$ & $\begin{array}{c}1 \\
(6.7 \%)\end{array}$ & $\begin{array}{c}0 \\
(0 \%)\end{array}$ & $\begin{array}{c}1 \\
(6.7 \%)\end{array}$ \\
\hline
\end{tabular}


How do you like the learning stations?

(all participants $(\mathrm{N}=222-227)$ )

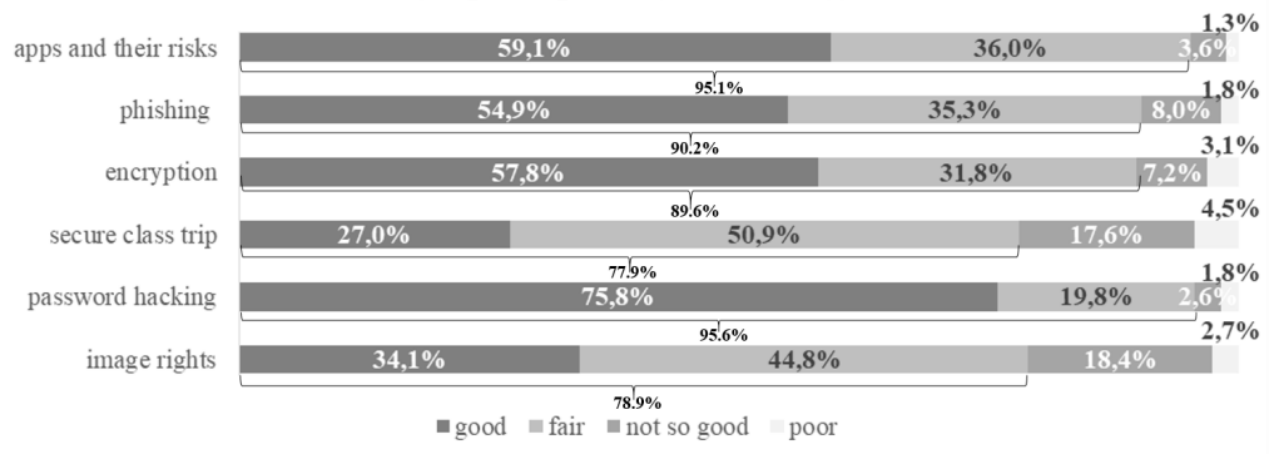

Figure 7. Popularity of the learnings stations among all participants

How do you like the learning stations?

(female participants $(\mathrm{N}=91-92)$ )

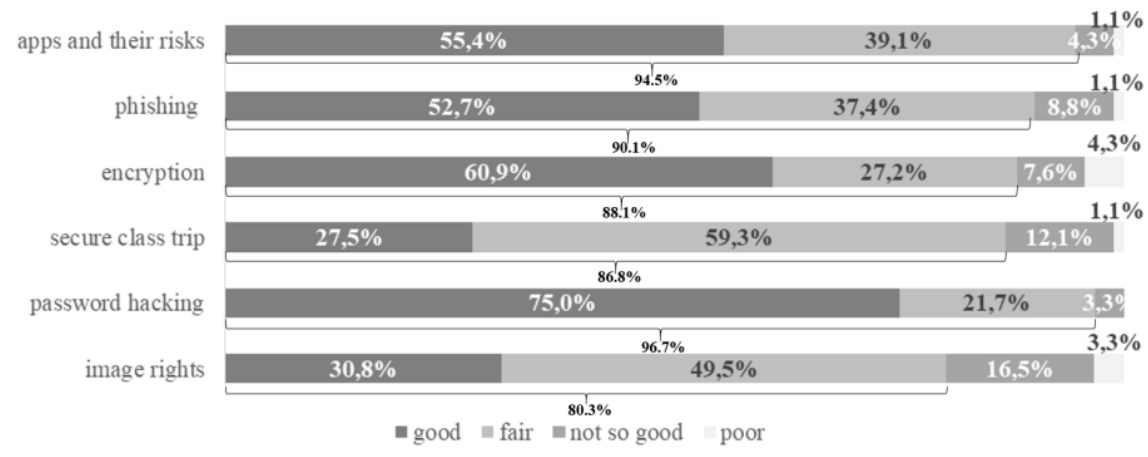

Figure 8. Popularity of the learnings stations among female participants

How do you like the learning stations?

(male participants $(\mathrm{N}=102-106)$ )

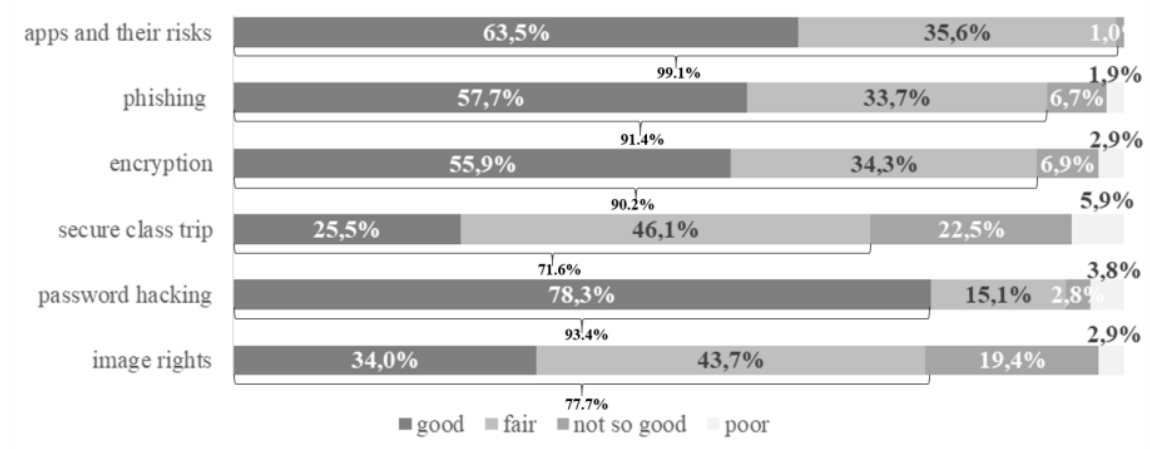

Figure 9. Popularity of the learnings stations among male participants 
In addition to looking at the preferences of participating pupils, we also examined the question of whether girls showed more interest in information security and computer science after completing the learning stations in single- or mixed-sex teams. The number of responses varied widely between the girlsonly and mixed-sex teams (72 and 18 respectively). Only somewhat fewer of the girls $(51.4 \%)$ who were part of single-sex teams agreed or tended to agree with the statement "I am interested in the topic information security", in comparison to 55.6 per cent of the girls in mixed-sex teams. For the statement "I am interested in computer science", the difference between girls in single-sex and mixed-sex teams is more striking44.4 per cent of the latter agreed or tended to agree, as against 29.2 per cent of the girls in girls-only teams.

Thus, in contrast to the research findings for subjects that tend to be seen as male domains, such as mathematics, natural sciences, and physics, our observations did not suggest that single-sex teams were more effective in tackling the learning stations related to information security and data protection. However, the limits of our investigation must be considered: our results need to be interpreted with caution and should only be seen as a preliminary insight in reply to the second research question because of the very small number of responses, in particular from the mixed-sex teams.

\section{Conclusion}

In answer to the question raised in the title of this paper- "How should we teach young adults to handle their sensitive information and personal data with caution?"- the very positive evaluation of the pilot action and the individual learning stations by the participating pupils militates in favour of a game-based approach as a means to sensitize young adults and foster a competent and responsible way of handling sensitive information and personal data. However, it should be noted that the six learning stations were developed within two years with several revisions.

Furthermore, based on the results, the first research question can be answered with a "yes". A vast majority of the pupils polled were interested in the learning stations dealing with important information security and data protection issues. Moreover, over three quarters of the young adults learned a considerable amount through the learning stations and would like to change their behaviour such that they handle their information and personal data with more caution. The statements relating to learning success and behavioural change met with greater approval among female participants. More than half of the girls and boys interviewed are also interested in information security. The difference between girls and boys is substantially lower than the variation in interest in computer science. Whereas boys are more interested in computer science, girls are more interested in information security.

With regard to the second research question, we did not observe a higher preference for single-sex teams among girls nor did we find that single-sex teams had any positive effects for girls. However, owing to our small sample size, especially for the mixedsex teams, these findings should be regarded as preliminary and interpreted with caution.

In order to ensure the sustainability of this project and the future use of the materials developed, schools and other institutions training pupils in information security and data protection are free to make use of the learning stations, which were developed in German.

\section{References}

[1] Medienpädagogischer Forschungsverbund Südwest (mpfs) (ed.) (2017) 'JIM 2017: Jugend, Information, (Multi-)Media; Basisstudie zum Medienumgang 12- bis 19Jähriger in Deutschland'; https://www.mpfs.de/fileadmin/files/Studien/JIM/2017/JIM_2017.pdf (11 May 2019).

[2] Jäger, M. and Schmitz, P. (2017) 'Studie von Kaspersky Labs Junge Frauen sehen wenig Anreiz in Karriere im ITSicherheitsumfeld', Security-Insider, 27 November 2017; https://www.security-insider.de/junge-frauen-sehen-weniganreiz-in-karriere-im-it-sicherheitsumfeld-a-663075/ (11 May 2019).

[3] Ashcraft, C., Eger, E. and Friend, M. (2012) Girls in IT: The Facts, National Center for Women \& Information Technology (NCWIT).

[4] Jin, G., Tu, M., Kim, T.-H., Heffron, J. and White, J. (2018) 'Game Based Cybersecurity Training for High School Students', in Proceedings of SIGCSE 2018, February 21-24, 2018, Baltimore, MD, USA, pp. 68-73.

[5] Rowland, P., Podhradsky, A. and Plucker, S. (2018) 'CybHER: A Method for Empowering, Motivating, Educating and Anchoring Girls to a Cybersecurity Career Path', in Proceedings of the $51^{\text {st }}$ Hawaii International Conference on System Sciences (HICSS), pp. 3727-3735.

[6] Linek, S. B. and Albert, D. (2009) 'Game-based Learning: Gender-Specific Aspects of Parasocial Interaction and Identification', in Proceedings of Conference: International Technology, Education and Development Conference (INTED)

[7] Deterding, S., Dixon, D., Khaled R. and Nacke, L. (2011) 'From Game Design Elements to Gamefulness: Defining "Gamification", in Proceedings of MindTrek.

[8] Codish, D. and Ravid, G. (2017) 'Gender Moderation in Gamification: Does One Size Fit All?', in Proceedings of the 50th Hawaii International Conference on System Sciences, pp. 2006-2015. 
[9] Silic, M. and Back, A. (2017) 'Impact of Gamification on User's Knowledge-Sharing Practices: Relationships between Work Motivation, Performance Expectancy and Work Engagement', in Proceedings of the 50th Hawaii International Conference on System Sciences 2017, pp. 13081317.

[10] Fang, X., Zhang, J. and Chan, S. S. (2013) 'Development of an Instrument for Studying Flow in Computer Game Play', International Journal of Human-Computer Interaction 29 (7), pp. 456-470.

[11] Wouters, P., van Nimwegen, C., van Oostendorp, H. and van der Spek, E. D. (2013) 'A Metaanalysis of the Cognitive and Motivational Effects of Serious Games', Journal of Educational Psychology 105 (2), pp. 249-265.

[12] Buffum, P. S., Boyer, K. E., Wiebe, E. N., Mott, B. W. and Lester, J. C. (2015) 'Mind the Gap: Improving Gender Equity in Game-Based Learning Environments with Learning Companions', in Proceedings of AIED: International Conferences on Artificial Intelligence in Education.

[13] Connolly, T. M., Boyle, E. A., MacArthur, E., Hainey, T. and Boyle, J. M. (2012) 'A Systematic Literature Review of Empirical Evidence on Computer Games and Serious Games', Computers \& Education 59 (2), pp. 661-686.

[14] Trybus, J. (2014) 'Game-Based Learning: What it is, Why it Works, and Where it's Going', New Media Institute; http://socialsciences.dadeschools.net/files/iCivics\%20Leaders\%20Institute/Game-Based\%20Learning_\%20What $\% 20$ it $\% 20$ is, $\% 20$ Why $\% 20$ it $\% 20$ Works, $\% 20$ and $\% 20$ Where $\% 20$ it's\%20Going.html (11 May 2019).

[15] Admiraal, W., Huizengab, J., Heemskerkc, I., Kuiperb, E., Volmanb, M. and Damb, G.t. (2014) 'Gender-inclusive Game-Based Learning in Secondary Education', International Journal of Inclusive Education 18 (11), pp. 12081218 .

[16] Bösche, W. and Kattner, F. (2011) 'Fear of (Serious) Digital Games and Game-Based Learning? Causes, Consequences and a Possible Countermeasure', International Journal of Game-Based Learning 1 (3), pp. 1-15.

[17] Helisch, M. and Pokoyski, D. (eds.) (2009) Security Awareness: Neue Wege zur erfolgreichen MitarbeiterSensibilisierung, Vieweg \& Teubner, Wiesbaden.

[18] Schneeweis, N. and Zweimüller, M. (2012) 'Girls, Girls, Girls: Gender Composition and Female School Choice', Economics of Education Review 31 (4), pp. 482500 .

[19] Kessels, U. and Hannover, B. (2008) 'When Being a Girl Matters Less: Accessibility of Gender-Related Knowledge in Single-sex and Coeducational Classes and Its Impact on Students' Physics-Related Self-Concept of Ability', British Journal of Educational Psychology 78 (2), pp. 273-289.

\section{Acknowledgements}

We wish to thank the Federal Ministry of Education and Research (BMBF) for funding the project. We would also like to thank the participating schools for their active involvement. 